\title{
Sustaining high energy efficiency in existing processes with advanced process integration technology
}

\author{
Nan Zhang ${ }^{\mathrm{a}, \mathrm{b}, *}$, Robin Smith ${ }^{\mathrm{a}, \mathrm{b}}$, Igor Bulatov ${ }^{\mathrm{a}}$, Jiří Jaromír Klemešc \\ ${ }^{a}$ Centre for Process Integration, School of Chemical Engineering and Analytical Science, The University of Manchester, Manchester M13 9PL, UK \\ ${ }^{\mathrm{b}}$ Process Integration Limited, One Central Park, Northampton Road, Monsall, Manchester M40 5BP, UK \\ ${ }^{\mathrm{c}}$ Centre for Process Integration and Intensification - $\mathrm{CPI}^{2}$, Research Institute of Chemical and Process Engineering, Faculty of Information Technology, \\ University of Pannonia, Egyetem u. 10, Veszprém 8200, Hungary
}

\section{A R T I C L E I N F O}

\section{Article history:}

Received 13 December 2011

Received in revised form 2 February 2012

Accepted 8 February 2012

Available online $\mathrm{xxxx}$

\section{Keywords:}

Process integration

Operation optimisation

Heat integrated distillation

\begin{abstract}
A B S T R A C T
To reduce emissions in the process industry, much emphasis has been put on making step changes in emission reduction, by developing new process technology and making renewable energy more affordable. However, the energy saving potential of existing systems cannot be simply ignored. In recent years, there have been significant advances in process integration technology with better modelling techniques and more advanced solution methods. These methods have been applied to the new design and retrofit studies in the process industry. Here attempts are made to apply these technologies to improve the environmental performance of existing facilities with operational changes. An industrial project was carried out to demonstrate the importance and effectiveness of exploiting the operational flexibility for energy conservation. By applying advanced optimisation technique to integrate the operation of distillation and heat recovery in a crude oil distillation unit, the energy consumption was reduced by $8 \%$ without capital expenditure. It shows that with correctly identified technology and the proper execution procedure, significant energy savings and emission reduction can be achieved very quickly without major capital expenditure. This allows the industry to improve its economic and environment performance at the same time.
\end{abstract}

() 2012 Elsevier Ltd. All rights reserved.

\section{Introduction}

The process industry is facing a great challenge to reduce their emissions while maintaining their competitiveness in the market economy. Much emphasis has been put on making step changes in emission reduction, by developing new process technology and making renewable energy more affordable. However, it would be a mistake if the flexibility of existing systems is not exploited fully in order to improve their energy performance.

Traditionally, the technology development of process integration has been mainly focused on the synthesis problems of process flow sheets in the chemical industry, with significant emphasis on energy conservation. Built on the early generation graphical approaches such as pinch analysis [1,2], in recent years, there have been significant advances in process integration technology [3]. Extension of the original pinch analysis, better modelling techniques and more advanced solution methods allow very complicated networks to be optimised at a much detailed level, with

* Corresponding author at: Centre for Process Integration, School of Chemical Engineering and Analytical Science, The University of Manchester, Manchester M13 9PL, UK.

E-mail address: nan.zhang@manchester.ac.uk (N. Zhang). typical examples in separation systems [4], heat recovery networks [5,6], utility systems [7], and total site analysis [8,9]. Many of these methods have been widely applied to the industry, to allow designs and retrofit studies to maximise the energy recovery $[10,11]$ and reduce $\mathrm{CO}_{2}$ emissions by improved process efficiency [12] and by process integration [13,14]. But the attempts of applying these technologies to improve the energy and environmental performance of existing facilities with operational changes are limited, due to major obstacles to bridge research outcomes with industrial applications, even though preliminaries academic calculations normally show significant savings could be achieved.

Through industrial demonstration projects, there are two main issues that have been highlighted to bridge the gaps: identification of suitable technologies, and practical and precise implementation strategies.

\section{Technology identification}

There are two key aspects in exploiting the potential of energy efficiency improvement in existing chemical processes. One is from individual unit operations, with the focus on better equipment design and optimal operating conditions. The other one is to integrate unit operations as a whole, using system engineering/process 
integration technology. Therefore, the discussion here will be focused on the latter aspect.

The constitution of chemical processes is best explained by the so-called "onion diagram" [15], shown in Fig. 1. It starts at the heart of the onion with the reactor and then moves outwards to the following layers: the separation system, the heat recovery system and the utility system.

In terms of energy conservation in chemical processes, each layer in the onion diagram has specific technical aspects to consider. In addition, there are certain interactions between these layers. Various process integration techniques have been developed to address these aspects, with typical examples mentioned in the Introduction. Such developments make it possible for us to look into the possibility of exploiting the potential of improving energy efficiency of existing systems with better operating strategies.

For operation optimisation, the problem can be considered as a subset of a new design problem for the same process. The essential internal physical models can remain the same as the ones for design and retrofit purposes, with additional constraints on equipment and operating conditions. However, these models can only be applicable to operation optimisation under three conditions: there are operating variables that can be manipulated to vary the energy performance of the process under investigation; the models can accurately reflect the performance variations of unit operations; and the computation time is sufficiently short to meet the requirement of operation monitoring and management. The three criteria have to be examined when it comes to the technology identification for system operation improvement. To illustrate these points, let us take a crude oil distillation process as an example.

Fig. 2 shows a typical flow sheet of a crude oil distillation unit. There are two main sections that are of our interest in the flow sheet. One is the distillation system, including an atmospheric distillation column, a vacuum distillation column, and a number of stripping columns for side-draw products. There are also pumparounds attached to the two main columns to remove heat at different temperature level and provide intermediate reflux. The other section is a heat exchanger network that achieves heat recovery by exchanging heat between the cold crude oil and hot product streams and pumparounds. Both sections have been a subject of investigation in the area of process integration since 1980s, and we have seen significant progress made in process design and retrofit to achieve energy conservation. Early methods were mainly based on thermodynamic principles for heat integration [2] and short-cut models for distillation system design [16]. They provided useful physical insights of the system energy efficiency and systematic approaches for conceptual design. However, the lack of accuracy makes these methods unsuitable for operation optimisation.

Due to improved solution methods and advances in computing technology, more accurate unit models have been developed and

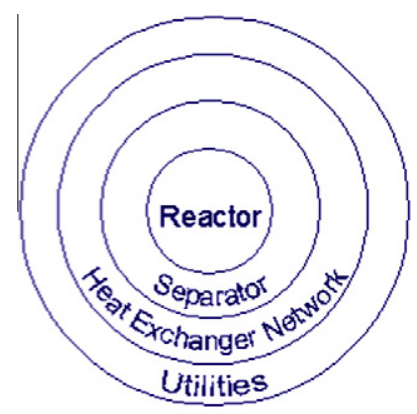

Fig. 1. "Onion diagram" of chemical processes. larger network models have been constructed and solved. For example, semi-rigorous distillation models have been developed for complex separation systems to replace short-cut models to improve the model accuracy [4]. For design of heat exchanger networks, the application of simulated annealing [17] into the solution method has vastly improved the quality of design solutions [18]. The issue of result accuracy seems no longer the bottleneck of operation optimisation. However, very few efforts have been made to apply these technologies for operation optimisation.

Under a fixed process configuration, the impact of changing operating conditions on energy efficiency may not be clear when a distillation system or a heat exchanger network is investigated individually using process integration techniques. In addition, an existing heat exchanger network itself has very limited options for changing its operating conditions at all. Therefore, these technologies along are not suitable for operation optimisation of such a process. The interactions between distillation operation and heat recovery has to be exploited simultaneously with their individual operating parameters, as shown in Fig. 3.

In this case, the key operating variables that affect the energy efficiency are the pumparound duties in both the atmospheric and the vacuum distillation columns, which have significant effects on both product qualities and heat recovery performance. In other words, pumparound duties are the key link between distillation operation and heat recovery. Therefore, in order to improve the energy efficiency by operation optimisation of crude oil distillation processes, it is essential that distillation and heat recovery can be optimised at the same time.

An integrated optimisation approach has been developed to achieve just that [5]. The detailed approach is shown in Fig. 4. There are two key technology advances in this approach. The first technology advance is a semi-rigorous modelling method for complex distillation systems. The method is still based on the decomposition method developed to simplify the calculation of complex distillation systems, as shown in Fig. 5. A series of simple columns are solved to provide better computation speed and convergence. The errors caused by the assumption of constant molar vapour/liquid flow in the traditional short-cut distillation model need to be corrected, while the expensive computation time with the rigorous stage-by-stage method commonly used in commercial simulation packages such as AspenPlus [19] and ProII [20] needs to be avoided. Therefore, a middle-way approach is adopted. The mass/ energy balance calculation for an overall distillation column as well as the key stages at the top and the bottom of each simple column under certain product specifications is incorporated into the short-cut model, as shown in Fig. 6 [5].

The second key technical advance is the integrated optimisation between distillation systems and heat recovery systems. The simulated annealing approach used for heat exchanger network optimisation [18] has been extended to cover both distillation optimisation variables and heat recovery variables, as shown in Fig. 7. Each move represents the change of each optimisation variable. Under the current computation power, this approach is only made feasible because of the developed semi-rigorous distillation model. The conventional short-cut model is not accurate enough to capture the interactions between distillation and heat recovery, while the rigorous stage-by-stage method is too time-consuming to be used in simulated annealing. Due to the random nature of the simulated annealing algorithm, each run may give a slightly different solution, which is why there is a need of multiple runs of simulated annealing to ensure the quality of the solution, as indicated in Fig. 4.

As can be seen in Fig. 7, key operating parameters such as reflux/reboiling, pumparound conditions, and heat exchanger duties, and their impact on product recovery are taken into consideration in this approach and can then be optimised simultaneously. This 


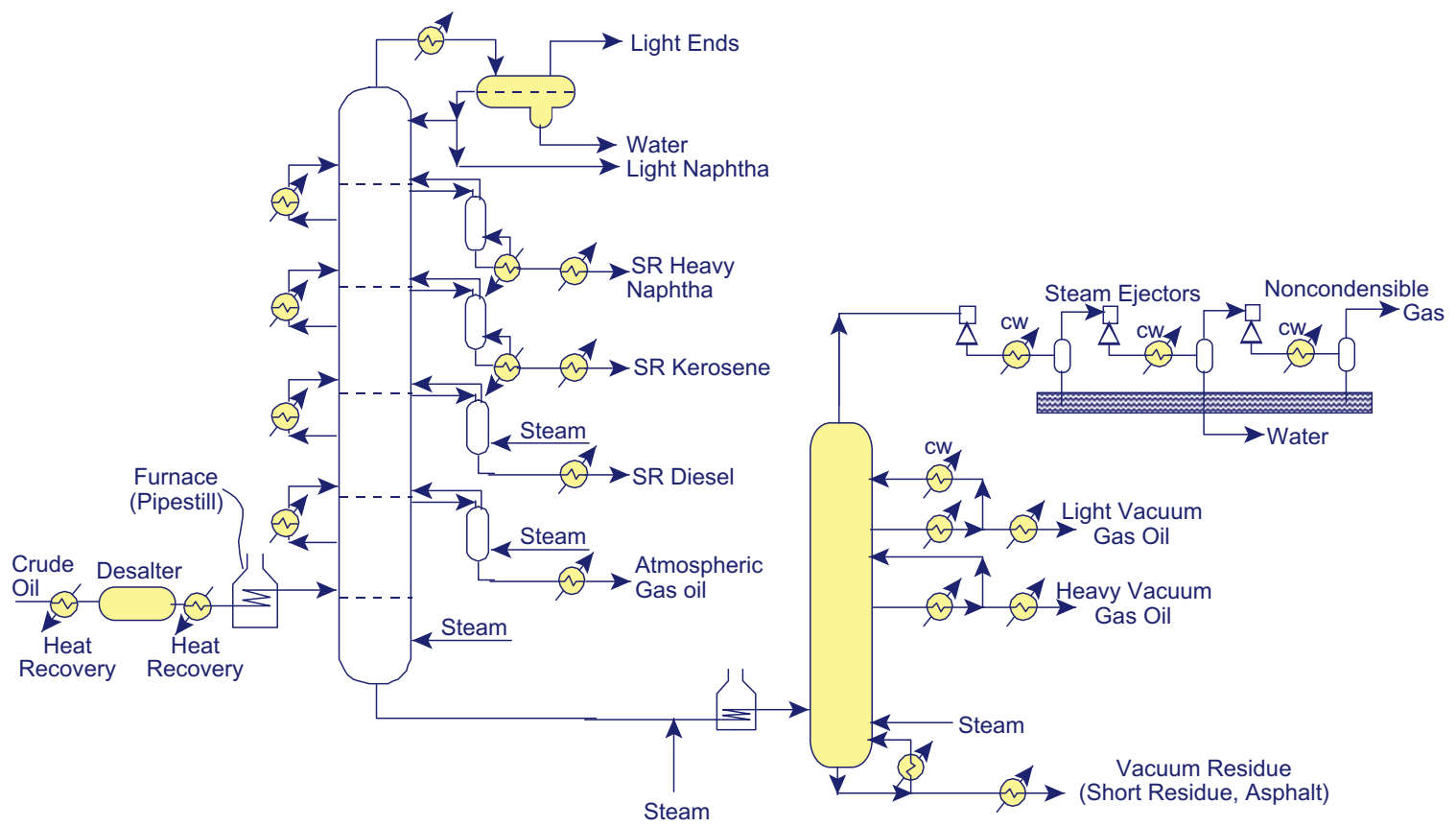

Fig. 2. Simplified flow sheet of crude oil distillation process.

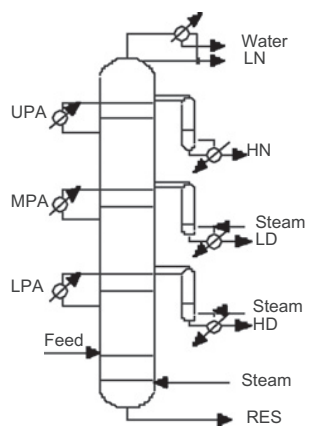

Column operation

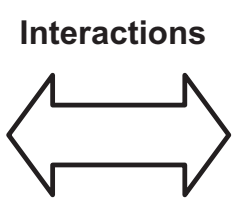

Heat recovery system operation

Fig. 3. Interactions between distillation and heat recovery.

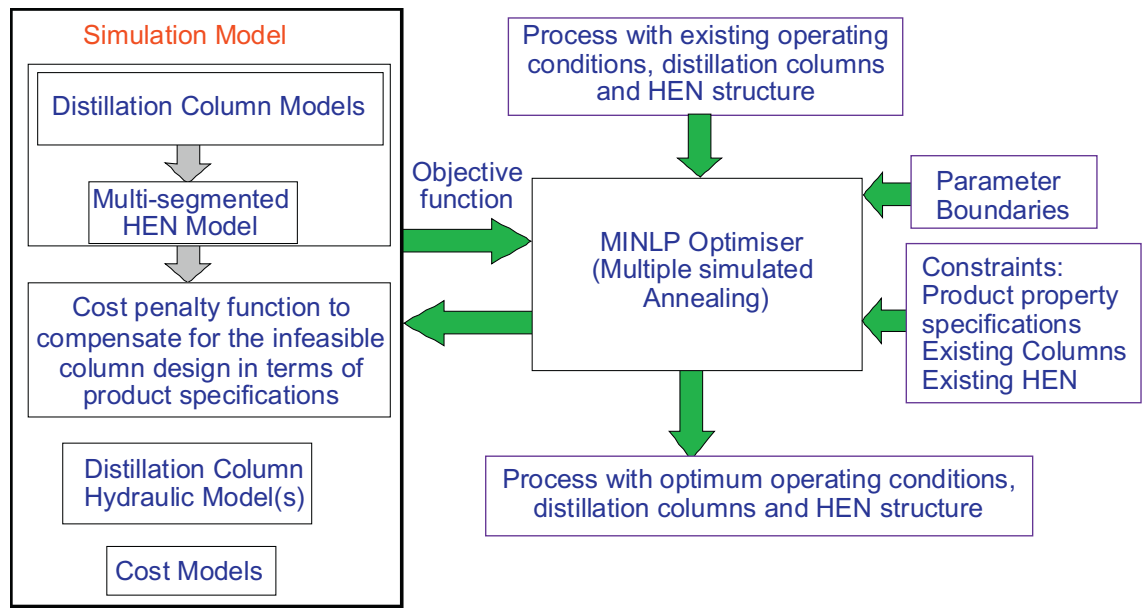

Fig. 4. Integration optimisation method for complex distillation systems.

makes it possible to be applied to operation optimisation for such complex separation systems. However, it is not so straightforward to achieve this goal. Extra care has to be taken in order to avoid mis-calculations that can cause severe operation upsets and economic losses. Therefore, a systematic procedure is needed for such technology implementation. 


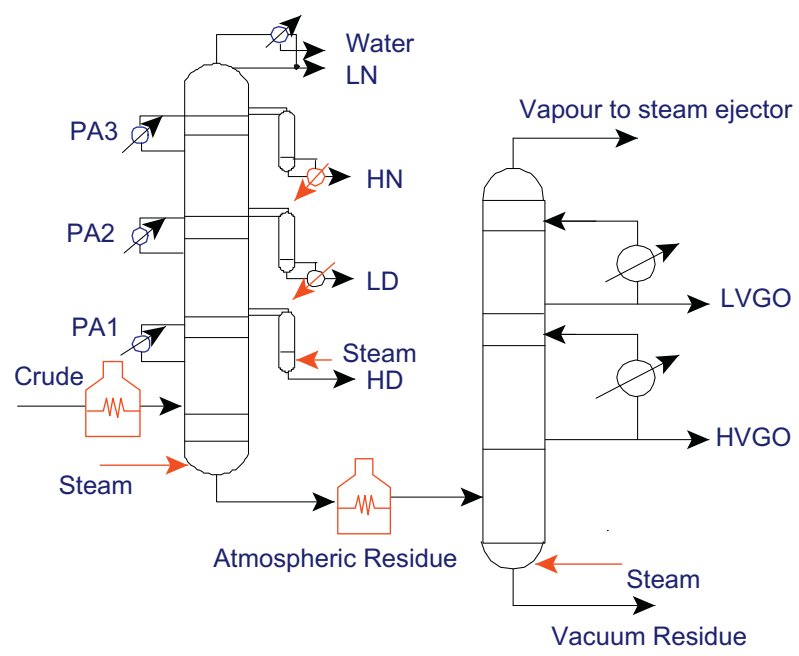

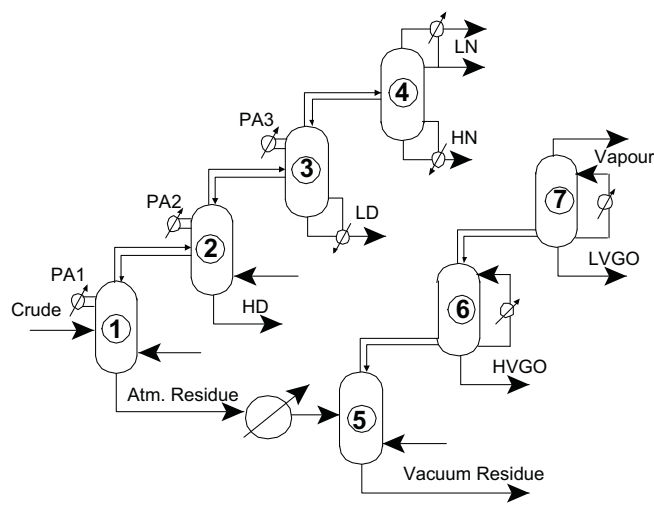

Decomposed sequence for optimisation

Fig. 5. Decomposition of complex distillation systems.

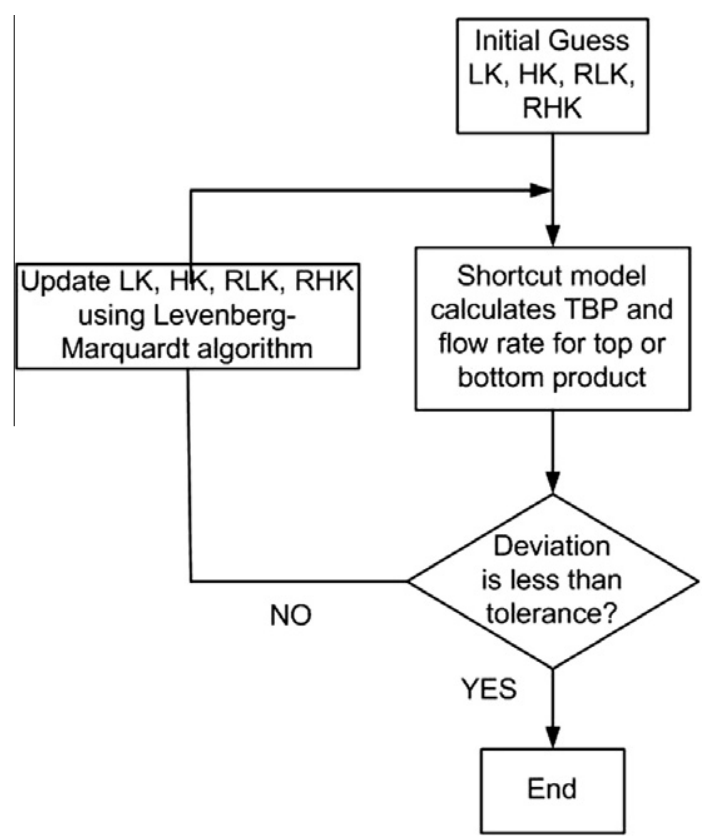

Fig. 6. Simple column modelling with product specifications.

\section{Systematic implementation strategy}

It is a common sense that we cannot put a blind trust on any model predictions no matter how good a model is supposed to be. However, it is not straightforward to match any model prediction to the reality and then provide valid instructions for improvement. There are four key stages in systematic implementation (Fig. 8): data collection, model development, model validation, and optimisation implementation.

Both operating data and design data are required in data collection. It is easy to understand why operating data such as temperatures, pressures, flow rates, and feed/product properties are required. The importance of collecting design data needs to be highlighted. Setting boundaries for practical constraints is critically important in formulating optimisation problems and obtaining sensible solutions. In order to identify correct boundaries on equipment performance and throughput limit, detailed design data of distillation columns and heat exchangers are needed to set out clear restrictions on column hydraulics and heat transfer capabilities of heat exchangers.

In model development, while the model building for heat exchangers is relatively straightforward, the model building for distillation is more challenging. To develop a semi-rigorous distillation model that is required in optimisation, a rigorous simulation model has to be developed first in order to reconcile the semi-rigorous model against the actual operation. The rigorous model generates essential information of detailed mass and energy balance within a distillation column, which is required to establish the semi-rigorous model. Therefore, it acts as a necessary link between the operating data and the optimisation model.

Both distillation models and heat exchanger models need to be verified before optimisation. This is the stage for data reconciliation and model updating. The rigorous distillation model can help to identify faulty measurements based on the fundamental principles of mass/energy balance and thermodynamics. However, for such a large and complex system, it is important to take into account the experience of operators, who can be very helpful to identify key potential problems that can cause mismatches. Still, it is quite common that several iterations between data collection and model building are required before an optimisation model can be satisfactorily verified. A close involvement of operating personnel can make this process more efficient.

Even with a reasonable looking optimisation model, extreme caution is required in implementation of optimisation results.

Firstly, suitable operating parameters must be identified for operation changes. Operation optimisation is only possible if such parameters are available. Secondly, process constraints need to be clearly defined and verified, in order to maintain product qualities and stability of process operation. For instance, column hydraulic calculations are required to set the limits on liquid and vapour flows within a distillation column in order not to cause operating upsets.

Thirdly, optimal operating strategy can then be determined using the developed process model with a complete set of constraints. By comparing the optimal solution and current operating conditions, key operating changes can be decided. To achieve a safe and smooth transition from the current operating point to the optimal point, an action plan needs to be carefully drawn out, and conservative small steps have to be taken. Corrective actions may be taken due to unexpected effects. During the implementation, the process conditions have to be closely monitored, and the model prediction needs to be adjusted accordingly. All these steps require close collaboration with process operators. 


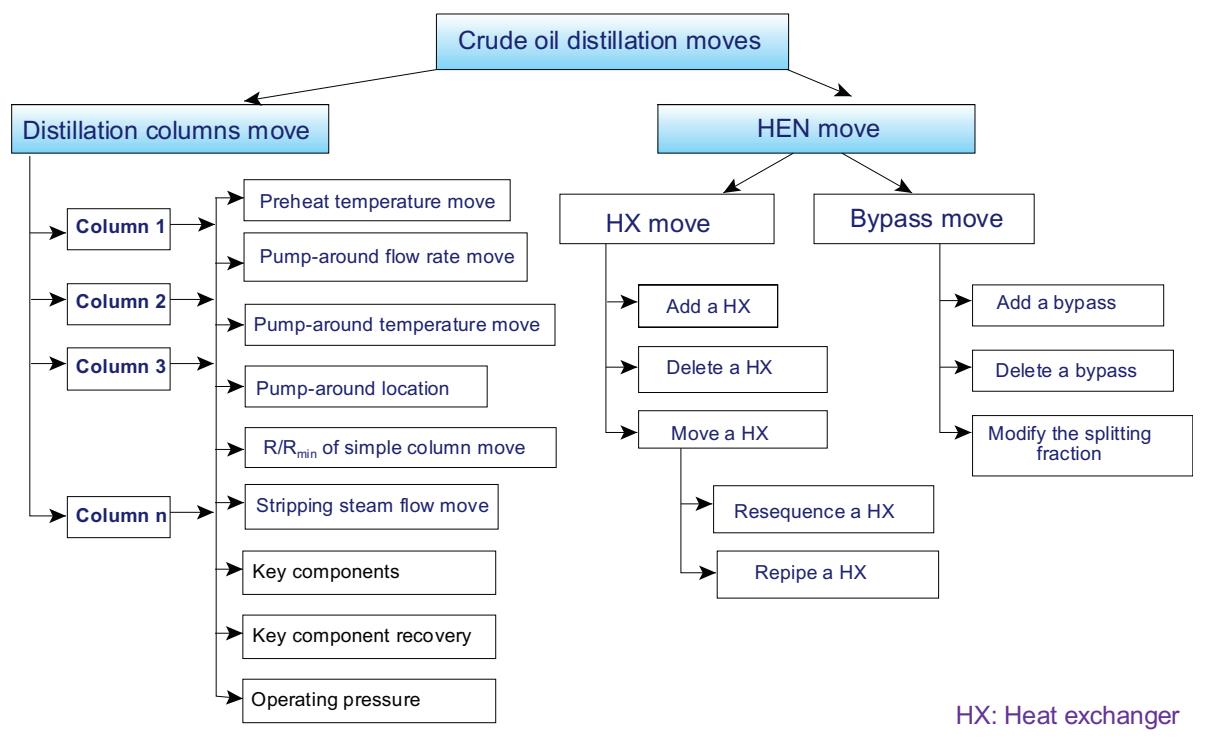

Fig. 7. Simulated annealing for integrated distillation system optimisation.

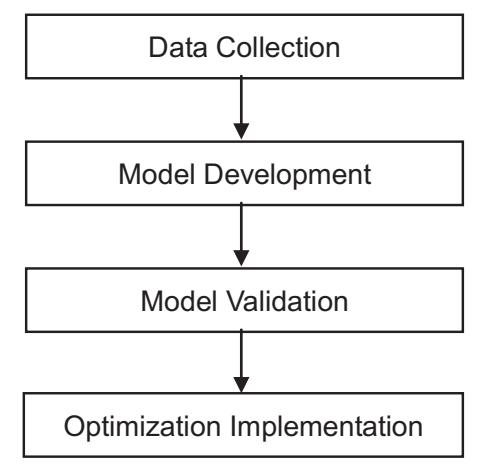

Fig. 8. Systematic procedure for operation optimisation.

\section{Case study}

An industrial demonstration project has been carried out on a commercial crude distillation unit in China. Due to confidentiality, sensitive client information is removed from the case study.

The throughput of the unit is $2.5 \mathrm{Mt} / \mathrm{y}$. And it has three main columns: a prefractionator, an atmospheric column, and a vacuum column. Crude oil is preheated in a heat exchanger network by exchanging heat with product streams and pumparounds. In the middle of the preheating, the prefractionator provides a preliminary separation to take out some light distillates. Then the crude oil goes into a furnace for final heating before entering the atmospheric column. A simplified flow sheet is shown in Fig. 9.

The key indicator of the energy efficiency of this unit is the inlet temperature of the atmospheric furnace, which is typically called as the coil inlet temperature (CIT). The higher the CIT, the more heat is recovered through the heat exchanger network, and therefore the more energy efficient. Hence, the aim of this project is to improve the CIT (currently at $255^{\circ} \mathrm{C}$ ) by operating adjustments only, without affecting the quality of all products.

The technology discussed earlier was therefore adopted in this project. First, the detailed mass and energy balance was established using rigorous simulation. Then the semi-rigorous model was calibrated. Together with the model of the heat exchanger network, it was implemented into a software package CDU-int developed by Process Integration Limited. A screen shot of the software is shown in Fig. 10.

The traditional pinch analysis was applied to analyse the current operation first. The pinch point was clearly identified, as shown in Fig. 11. After analysing the current operation, it was concluded that the current operation was clearly not at the optimal point, and the distribution of pumparound duties could be optimised to improve the energy recovery, without affecting the quality of products. It was estimated at this stage that CIT could be improved by $5{ }^{\circ} \mathrm{C}$ with operating changes only, and it was also predicted the actual improvement could be slightly different due to

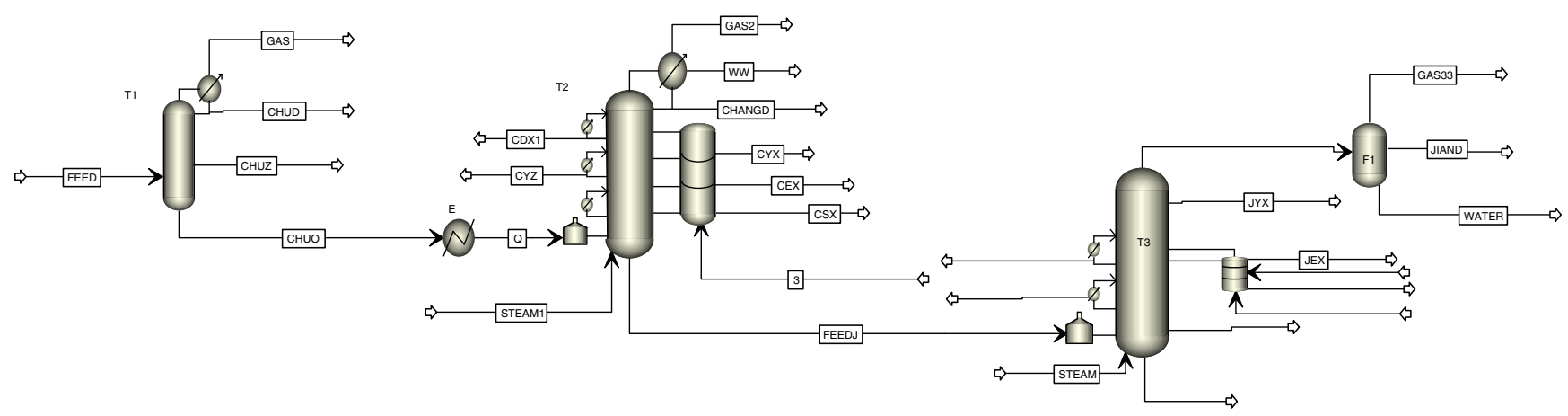

Fig. 9. Simplified process flow sheet. 


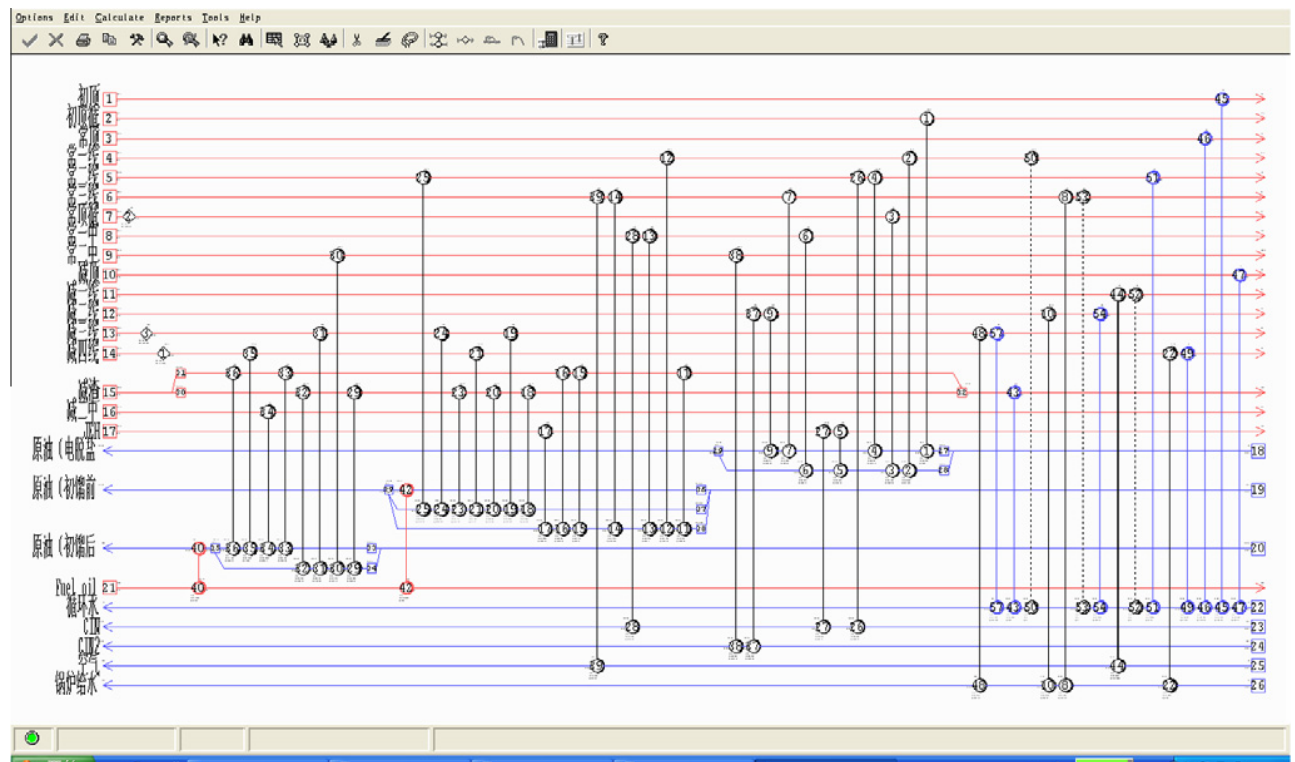

Fig. 10. Software interface.

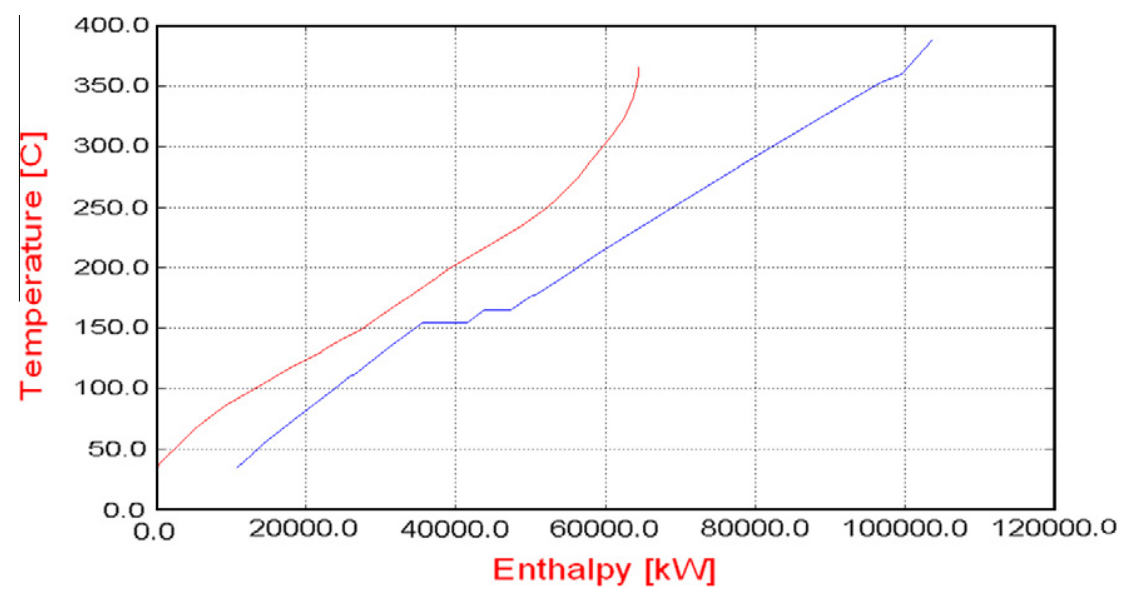

Fig. 11. Composite curve.

Table 1

Operating conditions before and after the implementation.

\begin{tabular}{lll}
\hline Item & Before & After \\
\hline Crude oil inlet $\left({ }^{\circ} \mathrm{C}\right)$ & 26 & 26 \\
Crude oil to desalter $\left({ }^{\circ} \mathrm{C}\right)$ & 112 & 115 \\
Crude oil to prefractionator $\left({ }^{\circ} \mathrm{C}\right)$ & 175 & 175 \\
$\mathrm{CIT}\left({ }^{\circ} \mathrm{C}\right)$ & 255.4 & 262.4 \\
Furnace outlet temperature $\left({ }^{\circ} \mathrm{C}\right)$ & 360 & 360 \\
Crude oil flow $\left(\mathrm{m}^{3} / \mathrm{h}\right)$ & 90 & 90 \\
$0.35 \mathrm{MPa}$ steam generation $(\mathrm{t} / \mathrm{h})$ & 8.8 (Daily average) & 10.15 (Daily average) \\
$1.0 \mathrm{MPa}$ steam generation $(\mathrm{t} / \mathrm{h})$ & 7.2 (Daily average) & 5.2 (Daily average) \\
\hline
\end{tabular}

uncertainties in measurement accuracy and actual equipment capability limit.

Then a careful working plan was drawn to decide the key action points and control/monitoring strategies. After keeping the current operation stable for several hours to set the basis for comparison, the implementation of operation changes followed. The effects were immediate. After $17 \mathrm{~h}$, the adjustment reached the desired set point, and CIT has been gradually increased from $255^{\circ} \mathrm{C}$ to $262{ }^{\circ} \mathrm{C}$. The comparison of operating conditions before and after the implementation is shown in Table 1.

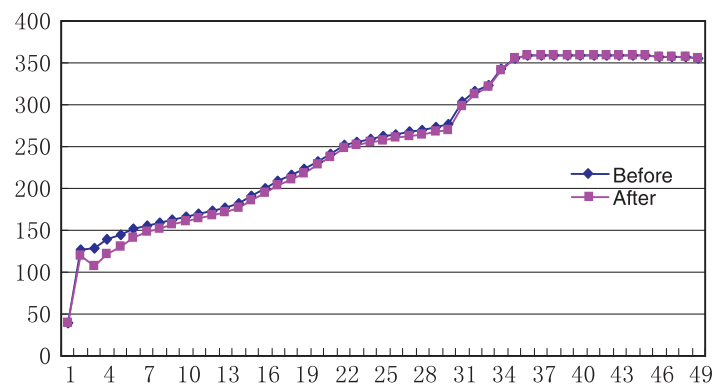

Fig. 12. Column temperature profile (Temp. vs. Stage).

During the process of increasing CIT, column temperature distribution and product quality were closely monitored. Between the starting point and the finishing point, as shown in Figs. 1216 , there were very small changes in the temperature distribution of the atmospheric column and the distillation curves of all the atmospheric products. All changes in product quality were within the specification limits. Therefore, the energy saving was achieved without sacrificing the product quality. 


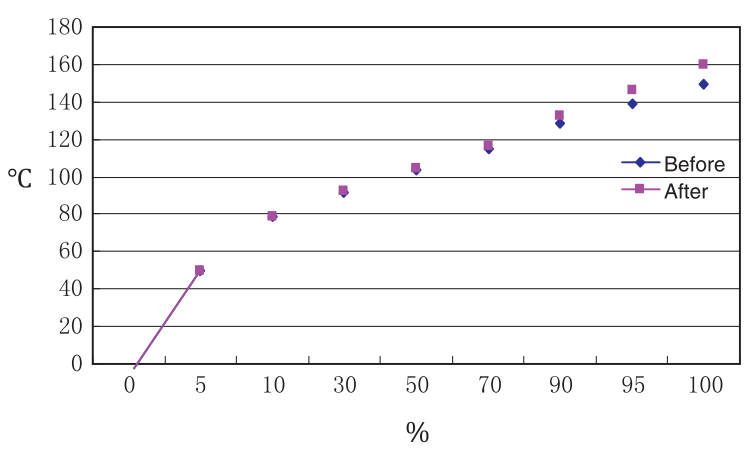

Fig. 13. ASTM D86 points of the overhead liquid product.

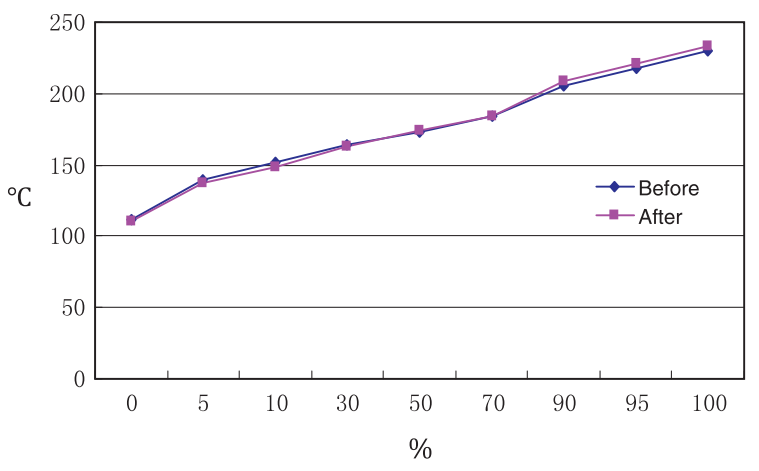

Fig. 14. ASTM D86 points of the first liquid side-draw.

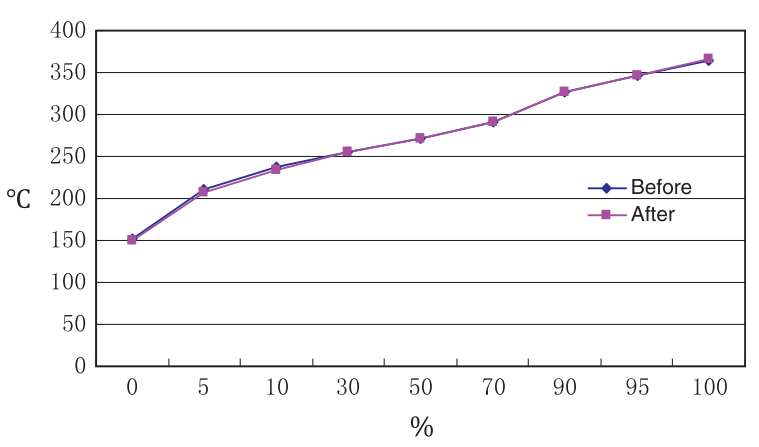

Fig. 15. ASTM D86 points of the second liquid side-draw.

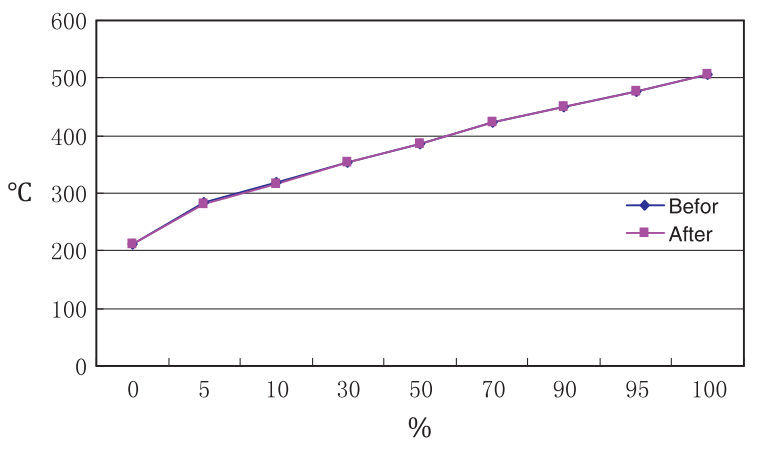

Fig. 16. ASTM D86 points of the third liquid side-draw.

The overall effects of the operation optimisation were significant. Within 1 day, the CIT has been increased by $7{ }^{\circ} \mathrm{C}$, equivalent to $8.2 \%$ reduction of the total energy consumption or the cost reduction of $1.23 \mathrm{MUS} \$ \mathrm{y}$. In order to compare the base case with the optimal case on the same basis, the duty of steam generation and air preheating was deliberately kept at the same level, which could be further adjusted to improve the energy efficiency.

As mentioned earlier, efficient computation is essential for successful operational monitoring and management. Simulated annealing is known for its requirement of heavy computing. In this case, by combining it with simplified semi-rigorous distillation model, the computation performance is just adequate for such an application. The calculation was carried out with a Windows PC using a Pentium Duo Core 2 processor, and it typically takes $0.5 \mathrm{~h}$ to reach a satisfactory solution.

\section{Conclusions}

As the industrial demonstration project has demonstrated, with correctly identified technology and the proper execution procedure, significant energy savings and emission reduction can be achieved very quickly without major capital expenditure. The development of process integration techniques has extended its applications from design and retrofit to operational optimisation, in which the economic performance and the environment performance of existing facilities can be taken into consideration simultaneously.

\section{Acknowledgements}

The financial support the EC FP7 Project "Intensified Heat Transfer Technologies for Enhanced Heat Recovery - INTHEAT", FP7-SME-2010-1-262205 is acknowledged by the authors.

\section{References}

[1] Townsend DW, Linnhoff B. Heat and power networks in process design. AIChE J 1983;29:742.

[2] Linnhoff B, Hindmarsh E. The pinch design method of heat exchanger networks. Chem Eng Sci 1983;38:745.

[3] Friedler F. Process integration, modelling and optimisation for energy saving and pollution reduction. Appl Therm Eng 2010;30:2270-80.

[4] Gadalla M, Jobson M, Smith R. Increase capacity and decrease energy in existing refinery distillation columns. Chem Eng Progr 2003:44-50.

[5] Chen L. Heat integrated crude distillation system design, PhD Thesis. UK: The University of Manchester; 2009.

[6] Feng X, Pu J, Yang J, Chu KH. Energy recovery in petrochemical complexes through heat integration retrofit analysis. Appl Energy 2011;88(5):1965-82.

[7] Varbanov PS, Doyle S, Smith R. Modelling and optimisation of utility systems. Trans IChemE 2004;82A:561-78.

[8] El-Halwagi M, Harell D, Spriggs HD. Targeting cogeneration and waste utilization through process integration. Appl Energy 2009;86(6):880-7.

[9] Wu B, Li J, Liu H, Zhang Z, Zhou Y, Zhao N. Energy information integration based on EMS in paper mill. Appl Energy 2012. doi:10.1016/i.apenergy.2011.12.021.

[10] Ebrahim M, Al- Kawari. Pinch technology: an efficient tool for chemical-plant energy and capital-cost saving. Appl Energy 2000;65(1-4):45-9.

[11] Ammar Y, Joyce S, Norman R, Wang Y, Roskilly AP. Low grade thermal energy sources and uses from the process industry in the UK. Appl Energy 2012;89(1):3-20.

[12] Siitonen S, Tuomaala M, Suominen M, Ahtila P. Implications of process energy efficiency improvements for primary energy consumption and $\mathrm{CO}_{2}$ emissions at the national level. Appl Energy 2010;87(9):2928-37.

[13] Lee SC, Ng DKS, Foo DCY, Tan RR. Extended pinch targeting techniques for carbon-constrained energy sector planning. Appl Energy 2009;86(1):60-7.

[14] Tiew BJ, Shuhaimi M, Hashim H. Carbon emission reduction targeting through process integration and fuel switching with mathematical modeling. Appl Energy 2012;92:686-93.

[15] Linnhoff B, Townsend DW, Boland D, Hewitt GF, Thomas BEA, Guy AR et al. A user guide on process integration for the efficient use of energy. last ed. IChemE, Rugby, UK 1982; 1994.

[16] Doherty MF, Malone MF. Conceptual design of distillation systems. New York: McGraw-Hill; 2001.

[17] Kirkpatrick S, Gellat CD, Vecchi MP. Optimisation by simulated annealing. Science 1983;220(4598):671-80.

[18] Rodriguez CA. Fouling mitigation strategies for heat exchanger networks. PhD Thesis, The University of Manchester, UK; 2005.

[19] Aspen Technology, Inc. <www.aspentech.com/products/aspen-plus.aspx>. [accessed 10.12.11].

[20] Invensys Inc. <iom.invensys.com/EN/Pages/SimSci-Esscor_ProcessEngSuite_ PROII.aspx>. [accessed 07.12.11]. 